\title{
Abuse-Related Effects of Dual Dopamine/Serotonin Releasers with Varying Potency to Release Norepinephrine in Male Rats and Rhesus Monkeys
}

\author{
Matthew L. Banks ${ }^{\# 1,2,{ }^{*}, \text { Clayton T. Bauer }}{ }^{\# 1}$, Bruce E. Blough ${ }^{3}$, Richard B. Rothman ${ }^{4}$, John \\ S. Partilla ${ }^{4}$, Michael H Baumann ${ }^{4}$, and S. Stevens Negus ${ }^{1,2}$ \\ ${ }^{1}$ Department of Pharmacology and Toxicology, Virginia Commonwealth University, Richmond, VA \\ USA \\ ${ }^{2}$ Institute for Drug and Alcohol Studies, Virginia Commonwealth University \\ ${ }^{3}$ Center for Organic and Medicinal Chemistry, Research Triangle Institute, Research Triangle \\ Park, NC USA \\ ${ }^{4}$ Medicinal Chemistry Section, Intramural Research Program, NIDA, Baltimore, MD USA \\ \# These authors contributed equally to this work.
}

\begin{abstract}
d-Amphetamine selectively promotes release of both dopamine (DA) and norepinephrine (NE) vs. serotonin (5HT), and chronic d-amphetamine treatment decreases cocaine-taking behavior in rats, nonhuman primates, and humans. However, abuse liability limits the clinical utility of amphetamine maintenance for treating cocaine abuse. One strategy to improve safety and efficacy of monoamine releasers as candidate anti-cocaine medications has been to develop dual DA/5HT releasers like 1-napthyl-2-aminopropane (PAL-287), but the pharmacology of this class of compounds has not been extensively examined. In particular, PAL-287 has similar potencies to release DA, 5HT and NE, and the role of manipulating NE release potency on abuse-related or anti-cocaine effects of dual DA/5HT releasers is not known. To address this issue, the present study compared effects of four novel DA/5HT releasers that varied $>800$-fold in their selectivities to release DA/5HT vs NE: [1-(5-chloro-1H-indol-3-yl)propan-2-amine (PAL-542), 1-(5fluoro-1H-indol-3-yl)propan-2-amine (PAL-544), 1-(1H-indol-5-yl)propan-2-amine (PAL-571), and (R)-1-(1H-indol-1-yl)propain-2-amine (PAL-569). Abuse-related effects of all four compounds were evaluated in assays of intracranial self-stimulation (ICSS) in rats and cocaine discrimination in rats and monkeys, and none of the compounds reliably facilitated ICSS or substituted for cocaine. Anti-cocaine effects of the compound with highest selectivity to release DA/5HT vs. NE (PAL-542) were tested in an assay of cocaine vs. food choice in rhesus monkeys, and PAL-542 failed to reduce cocaine choice. These results suggesst that potency to release NE has minimal influence on abuse liability of dual DA/5HT releasers, and reducing relative potency to release NE vs. DA/5HT does not improve anti-cocaine efficacy.
\end{abstract}

*Corresponding Author: Department of Pharmacology and Toxicology Virginia Commonwealth University 410 N. $12^{\text {th }}$ St. PO Box 980613 Richmond, VA 23298 mbanks7@ vcu.edu Phone: 804-828-8466 Fax: 804-828-2117.

There are no real or potential conflicts of interest to disclose by any of the authors. 


\section{Keywords}

cocaine; choice; dopamine; norepinephrine; serotonin

\section{INTRODUCTION}

Monoamine releasers constitute one class of compounds being investigated as candidate anti-cocaine addiction medications. Specifically, chronic treatment with the dopamine (DA) / norepinephrine (NE) vs. serotonin (5HT)-selective monoamine releaser damphetamine has decreased cocaine self-administration in rats (Chiodo, Läck, \& Roberts, 2008; Thomsen, Barrett, Negus, \& Caine, 2013), nonhuman primates (Czoty, Gould, Martelle, \& Nader, 2011; Negus, 2003), human laboratory studies (Greenwald, Lundahl, \& Steinmiller, 2010; Rush, Stoops, Sevak, \& Hays, 2010), and clinical trials (Grabowski et al., 2001; Grabowski, Rhoades, et al., 2004). However, d-amphetamine has high abuse liability that limits its clinical utility, and cocaine addiction treatment might benefit from identification of novel monoamine releasers that have reduced abuse liability while retaining efficacy to decrease cocaine-taking behavior. One strategy to reduce abuse liability of monoamine releasers, and perhaps enhance their therapeutic effectiveness, has been to develop compounds that release 5HT as well as DA. This approach is founded on the hypothesis that serotonergic effects would oppose DA-mediated abuse-related effects while also ameliorating dual deficits in both DA and 5HT signaling that occur during stimulant withdrawal (Kampman et al., 2000; Rothman, Blough, \& Baumann, 2008). For example, PAL-287 (1-napthyl-2-aminopropane) was identified as a "dual DA/5HT releaser" with similar potency to release DA and 5HT, and it produced relatively weak effects in conventional abuse liability preclinical behavioral procedures (Rothman et al., 2005). However, in contrast to chronic d-amphetamine, chronic treatment with PAL-287 produced a non-selective decrease in both cocaine- and food-maintained responding (Banks, Blough, \& Negus, 2011; Negus, Mello, Blough, Baumann, \& Rothman, 2007; Rothman et al., 2005). These non-selective behavioral effects were interpreted to suggest that, despite its function as a dual DA/5HT releaser, PAL-287 would be more likely than d-amphetamine to produce undesirable effects at doses sufficient to reduce cocaine use.

In addition to promoting dual release of both DA and 5HT, PAL-287 also has a similar high potency to release NE (Rothman et al., 2005), and the influence of NE release on abuserelated and anti-cocaine effects of PAL-287 and other monoamine releasers is unclear. Prevailing evidence suggests that NE plays a minimal role compared to DA in the reinforcing effects of amphetamine-type monoamine releasers as assessed under standard drug self-administration procedures (Risner \& Jones, 1976; Woolverton, 1987). However, NE effects do appear to contribute to the discriminative stimulus effects of monoamine releasers in rats (Tongjaroenbuangam, Meksuriyen, Govitrapong, Kotchabhakdi, \& Baldwin, 1998) and monkeys (Anderson, Winger, Woods, \& Woolverton, 2001; Kamien \&

Woolverton, 1989) and to abuse-related subjective effects in humans (Rothman et al., 2001). NE may also contribute to undesirable sympathomimetic effects related to sleep, thermoregulation, cardiovascular function, and anxiety (Grabowski et al., 2001). Taken 
together, these results suggest that NE release may contribute to undesirable effects of monoamine releasers.

In view of the potential promise of dual DA/5HT releasers and the unspecified role of NE in mediating therapeutic and/or undesirable effects of these compounds, the present study evaluated effects of four novel DA/5HT releasers that varied in their in vitro selectivity for releasing DA/5HT vs. NE (PAL-542, PAL-544, PAL-571, PAL-569; see Figure 1 and Table 1). Specifically, like PAL-287, these compounds all have similar potencies to release DA and $5 \mathrm{HT}$ but a $>800$-fold range in their potencies to release DA vs. NE. The primary aim of this study was to compare abuse-related behavioral effects of these novel monoamine releasers with effects of three reference monoamine releasers (d-amphetamine, PAL-287 and fenfluramine; Figure 1) in intracranial self-stimulation (ICSS) in rats and cocaine discrimination in both rats and rhesus monkeys. Cocaine was the training stimulus because one potential application for novel monoamine releasers is to treat cocaine addiction (Grabowski, Shearer, Merrill, \& Negus, 2004; Stoops \& Rush, 2013). We hypothesized that, as with PAL-287, the presence of serotonergic effects would suppress expression of DAmediated abuse-related effects across all compounds. A secondary aim of the study was to determine effects of the most DA/5HT- vs. NE-selective compound (PAL-542) in a cocainevs.-food choice procedure in rhesus monkeys that has been used previously to evaluate effects of d-amphetamine, PAL-287, fenfluramine, and other monoamine releasers (Banks et al., 2011; Negus, 2003). We hypothesized that reduced noradrenergic effects might result in improved selectivity of PAL-542 vs. PAL-287 to reduce cocaine choice.

\section{METHODS}

\section{In Vitro Assay of Monoamine Release}

Potencies and selectivities of PAL-542, PAL-544, PAL-571, and PAL-569 to evoke release via rat monoamine transporters (rSERT, rNET, and rDAT) were determined in rat brain synaptosomes as previously described (Baumann et al., 2012). Rats were euthanized with $\mathrm{CO}_{2}$, decapitated, and brains were rapidly removed and dissected on ice. Synaptosomes were prepared from striatum for rDAT assays, whereas synaptosomes were prepared from whole brain minus striatum and cerebellum for the rNET and rSERT assays. $\left[{ }^{3} \mathrm{H}\right] 1-$ Methyl-4-phenylpyridinium $\left(\left[{ }^{3} \mathrm{H}\right] \mathrm{MPP}+\right)(9 \mathrm{nM})$ was used as the radiolabeled substrate for DAT and NET, while $\left[{ }^{3} \mathrm{H}\right] 5-\mathrm{HT}(5 \mathrm{nM})$ was used as a substrate for SERT. All buffers used in the release assays contained $1 \mu \mathrm{M}$ reserpine to block vesicular uptake of substrates. The selectivity of assays was optimized for a single transporter by including unlabeled compounds (nomifensine and GBR12935 for SERT; GBR12935 and citalopram for NET; citalopram and desipramine for DAT) to prevent the uptake of $\left[{ }^{3} \mathrm{H}\right] \mathrm{MPP}+$ or $\left[{ }^{3} \mathrm{H}\right] 5-\mathrm{HT}$ by competing transporters. Synaptosomes were preloaded with radiolabeled substrate in Krebsphosphate buffer for $1 \mathrm{~h}$ (steady state). Assays were initiated by adding $850 \mu \mathrm{L}$ of preloaded synaptosomes to $150 \mu \mathrm{L}$ of test drug. Assays were terminated by vacuum filtration, and retained radioactivity was quantified by liquid scintillation counting. $\mathrm{EC}_{50}$ values were determined using nonlinear least-squares curve fitting (GraphPad Prism, San Diego, CA). Transporter selectivities were calculated as ratios of $\mathrm{EC}_{50}$ values to promote release for DA vs. $\mathrm{NE}\left(\mathrm{EC}_{50}\right.$ at $\mathrm{rDAT} / \mathrm{EC}_{50}$ at $\left.\mathrm{rNET}\right)$ and for DA vs. $5-\mathrm{HT}\left(\mathrm{EC}_{50}\right.$ at $\mathrm{rDAT} / \mathrm{EC}_{50}$ at $\left.\mathrm{rSERT}\right)$. 


\section{Intracranial Self-Stimulation Procedure}

Subjects-Studies were conducted using previously described procedures (Bauer, Banks, Blough, \& Negus, 2013). Subjects were 5 male Sprague Dawley rats (Harlan, Frederick, MD) that had ad libitum access to standard rodent laboratory chow and continuous access to water in their home cage. Rats were individually housed on a 12 hour light-dark cycle, and studies were conducted during the light cycle. Experimental protocols complied with the $8^{\text {th }}$ edition of the Guide for the Care and Use of Laboratory Animals and were approved by the Institutional Animal Care and Use Committee. Furthermore, animal facilities were licensed by both the United States Department of Agriculture and the Association for Assessment and Accreditation of Laboratory Animal Care.

Surgery-Subjects were anesthetized using $2.5 \%$ isoflurane gas and the cathode $(0.25 \mathrm{~mm}$ diameter) of a bipolar electrode was stereotaxically inserted: $2.8 \mathrm{~mm}$ posterior to Bregma, $1.7 \mathrm{~mm}$ lateral to the midsaggital line, and $8.8 \mathrm{~mm}$ ventral to the skull. Three stainless steel screws were placed in the skull, and the anode $(0.125 \mathrm{~mm}$ diameter, uninsulated) was wrapped around one of these screws to act as a ground. Dental acrylic was used to secure the electrode. Animals were allowed at least 5 recovery days before ICSS training.

Apparatus-Operant chambers consisted of sound-attenuating boxes containing modular acrylic and metal test chambers. Each chamber had a response lever, three stimulus lights (red, yellow, and green) centered above the response lever, a 2-W house light, and an ICSS stimulator (Med Associates, St. Albans, VT, USA). Bipolar cables routed through a swivelcommutator connected the stimulator to the electrode (Model SL2C, Plastics One, Roanoke, VA, USA). Med-PC IV (Med Associates) software controlled all programming parameters and data collection.

Training-Animals were trained to respond under a fixed-ratio (FR) 1 schedule of reinforcement for a 0.5 -s train of square-wave cathodal pulses $(0.1 \mathrm{~ms} /$ pulse). Stimulations were available during three consecutive daily components, and each 10 min component consisted of ten 1-min trials. The available stimulation frequency for the first trial was 158 $\mathrm{Hz}(2.2 \log \mathrm{Hz})$ and frequency decreased by $0.05 \log$ units during each of the subsequent 9 trials to a final frequency of $56 \mathrm{~Hz}(1.75 \log \mathrm{Hz})$. Each trial started with a $10 \mathrm{~s} \mathrm{time-out}$ period, during which responding had no scheduled consequences, and 5 non-contingent stimulations at the designated frequency were delivered at one second intervals during the last $5 \mathrm{~s}$ of the time out. During the remaining 50s of each trial, responding produced both intracranial stimulation at the designated frequency and illumination of the lever lights. Stimulation intensity was individually adjusted to identify an intensity that maintained greater than half-maximal responding at the 5 highest frequencies. Once this intensity was identified, training continued until group mean frequency-rate curves were not statistically different over three consecutive training days.

Testing-For dose-effect studies, behavioral sessions consisted of three consecutive "baseline" components and three consecutive "test" components separated by a 20-min time out period. Saline or a dose of PAL-542, PAL-544, PAL-571, or PAL-569 was administered intraperitoneal (IP) at the beginning of this 20 -min time out. Time course studies consisted 
of three consecutive "baseline" components followed by IP administration of a single drug dose and then two consecutive test components beginning 10, 30, 100, and 300 min after drug administration. Test sessions were usually conducted on Tuesdays and Fridays, and training sessions were conducted on Mondays and Thursdays. Dose-effect studies were completed before time course studies, and experiments with one compound were generally completed in a given rat before initiating studies with the next compound.

Data Analysis-Data were analyzed to provide summary measures of drug efficacies to facilitate ICSS as previously described (Bauer et al., 2013). Briefly, mean total stimulations across all ten frequency trials were calculated from the second and third "baseline" components. Data from the first "baseline" component was not included in the analysis because this first component was conventionally considered as a "warm-up" and was discarded from analysis (Carlezon \& Chartoff, 2007). Test data were normalized to individual baseline data using the equation $\%$ baseline total stimulations per component $=$ (mean total stimulations per test component)/(mean total stimulations per baseline component) x 100. Data were then averaged across rats for each experimental condition. Two-way repeated-measures ANOVAs were used with test compound as one factor and dose or time as the second factor. A Holm-Sidak post-hoc test followed significant ANOVAs, and $p<0.05$ was considered significant.

\section{Cocaine Discrimination Procedure in Rats}

Subjects-Studies were conducted using previously described procedures (Caine, Negus, Mello, \& Bergman, 2000). Subjects were 10 male Sprague Dawley rats (Charles River Laboratories, Wilmington, MA, or Harlan, Frederick, MD) maintained at body weights of $300-370 \mathrm{~g}$ by standard rodent laboratory chow delivered after behavioral sessions. Other details are identical to those described above for subjects in ICSS studies.

Apparatus-Each operant chamber, as described above, had two response levers, a panel of three stimulus lights (red, yellow, and green) centered above each response lever, and a pellet dispenser located between the two levers (Med Associates) for delivery of $45 \mathrm{mg}$ rodent grain-based diet pellets (Bioserv, Frenchtown, NJ).

Training Procedure-After initial shaping of food-maintained responding under a conjoint fixed-time 4 min: FR 1 schedule of reinforcement, rats were trained to discriminate $5.6 \mathrm{mg} / \mathrm{kg}$ cocaine IP from saline in a two-key, food-reinforced drug discrimination procedure. Discrimination training was conducted 5 days/week during daily sessions consisting of a 10-min response period, during which stimulus lights were illuminated over both levers, and rats could earn up to 25 food pellets by responding under a FR10 schedule of food presentation. If all 25 pellets were delivered before $10 \mathrm{~min}$ elapsed, then all stimulus lights were extinguished, and responding had no further scheduled consequences. Saline or $5.6 \mathrm{mg} / \mathrm{kg}$ cocaine was administered $10 \mathrm{~min}$ prior to the start of the response period in a double alternating pattern across days. Saline and cocaine-associated levers were counterbalanced between animals. Responses on the injection-inappropriate lever reset the response requirement on the injection-appropriate lever. The criterion for accurate discrimination was $\geq 75 \%$ injection-appropriate responding before delivery of the first reinforcer, $\geq 90 \%$

Exp Clin Psychopharmacol. Author manuscript; available in PMC 2015 June 01. 
injection-appropriate responding for the entire session, and responses rates $>0.02$ responses/sec (sufficient to earn at least one pellet) for 5 of 6 consecutive sessions.

Testing Procedure-Test sessions were identical to training sessions except (1) completion of the response requirement on either lever produced food, and (2) test drugs were administered as described below. Test sessions were typically conducted on Tuesdays and Fridays and only conducted if criteria 1 and 2 above had been met during the preceding training session. The pretreatment time for $\mathrm{d}$-amphetamine was $20 \mathrm{~min}$. The pretreatment time for all other compounds (fenfluramine, PAL-287, PAL-542, PAL-544, PAL-571, and PAL-569) was $10 \mathrm{~min}$. With one exception (fenfluramine), the drug dose tested in time course studies was the lowest dose to produce $\$ 90 \%$ cocaine-appropriate responding or to eliminate responding in at least one rat in the dose-effect studies. The fenfluramine time course was tested with a dose $(3.2 \mathrm{mg} / \mathrm{kg})$ previously shown to produce a slow onset of ratedecreasing effects (Bauer et al., 2013). For time course studies, different pretreatment times (10-300 $\mathrm{min})$ were tested in different test sessions. Dose-effect studies were conducted before time course studies, and both dose and pretreatment time were tested in ascending order. In addition, all tests were completed with a given compound in a given rat before initiation of testing with another compound. Each drug was tested in a group of 5 or 6 rats.

Data Analysis-The primary dependent measures were (1) percent cocaine-appropriate responding (\%CAR) for the entire session \{defined as (number of responses on the cocaineassociated key divided by the total number of responses on both the cocaine-and salineassociated keys)*100\}, and (2) rates of responding in responses per second. These dependent measures were then plotted as a function of dose or time after test drug administration. Test compounds that produced $\geq 90 \%$ cocaine-appropriate responding for the entire session were considered to produce full substitution, and to summarize results, the percentage of subjects in which full substitution was observed at any dose or time was determined for each test compound.

\section{Cocaine Discrimination Procedure in Monkeys}

Subjects-Subjects were 5 adult male rhesus monkeys (Macaca mulatta) with an experimental history involving exposure to primarily monoaminergic compounds (Banks, Blough, Fennell, Snyder, \& Negus, 2013b). Monkeys were maintained on a diet of fresh fruit and food biscuits (Lab Diet High Protein Monkey Biscuits \#5045, PMI Nutrition Inc., St. Louis, MO) provided after the behavioral session. Water was continuously available in the home cage. Monkeys had continuous visual, auditory and olfactory contact with other monkeys. In addition, operant procedures and foraging toys were provided for environmental manipulation and enrichment. Videos or music were played to provide additional environmental enrichment. Light-dark cycle and of regulatory compliance details are identical as described above for rats.

Apparatus-The front door of the housing chamber, which also served as the experimental chamber, was equipped with a response panel that included three square response keys arranged horizontally; only the left and right keys were used in the present experiments. 
Attached to the panel was a pellet dispenser (Med Associates, ENV-203-1000) for delivery of 1-gram banana-flavored pellets (Test Diets, Richmond, IN).

Discrimination Training-Monkeys were trained to discriminate $0.32 \mathrm{mg} / \mathrm{kg}$ cocaine from saline in a two-key, food-reinforced drug discrimination procedure. Behavioral sessions were conducted 5 days/week and were composed of three components presented at 2-h intervals. Each component consisted of a 5-min response period, during which the right and left response keys were illuminated red and green, respectively, and monkeys could earn up to 10 food pellets by responding under a FR 30 schedule of food presentation. Either saline or $0.32 \mathrm{mg} / \mathrm{kg}$ cocaine was administered via intramuscular (IM) injection $15 \mathrm{~min}$ prior to the start of each component. This $2 \mathrm{~h}$ inter-component interval was selected to exceed the time course of discriminative stimulus effects produced by the training dose of cocaine (Lamas, Negus, Hall, \& Mello, 1995). Thus, on training days, monkeys would receive a sequence of saline and cocaine injections and sequences were randomly presented.

Responses on the injection-inappropriate key reset the FR requirement on the injectionappropriate key. The criterion for accurate discrimination was $\$ 80 \%$ injection-appropriate responding before delivery of the first reinforcer, $\$ 0 \%$ injection-appropriate responding for the entire component, and response rates $>0.1$ responses/sec (sufficient to earn at least one pellet) for all components during 7 of 8 consecutive sessions.

Discrimination Testing-Test sessions were identical to training sessions except (1) completing the response requirement on either key produced food and (2) 5-min response components began 10, 30, 56, 100, 180, 300, and 560 min after an IM injection of the test drug dose. d-Amphetamine, PAL-287, ( \pm )-fenfluramine, PAL-542, PAL-544, PAL-571, and PAL-569 were tested up to doses that either produced full substitution for the training cocaine dose or that significantly decreased rates of operant responding. Test sessions were separated by at least 3 days were only conducted if criteria for accurate discrimination were met during the previous two training sessions. All test drug doses were tested once in each monkey and both drug dose and drug order were counterbalanced between monkeys. All doses of a given test drug were evaluated in a given monkey before testing the next drug, and vehicle (saline) test sessions were conducted either before or after evaluation of each test drug.

Data Analysis-The primary dependent measures were the same as described above in cocaine discrimination procedure in rats. Test compounds that produced $\searrow 90 \%$ cocaineappropriate responding were considered to produce full substitution, and to summarize results, the percentage of subjects in which full substitution was observed at any dose or time was determined for each test compound.

\section{Cocaine vs. Food Choice Procedure in Monkeys}

Subjects-Studies were conducted using previously described procedures (Banks et al., 2011). Subjects were 5 adult male rhesus monkeys implanted with an indwelling doublelumen venous catheter (Reiss Manufacturing, Blackstone, VA or STI Flow, Morrisville, NC). All monkeys had cocaine self-administration histories (Banks, Blough, Fennell, 
Snyder, \& Negus, 2013a; Banks, Blough, \& Negus, 2013). Other subject details are identical to those described above for subjects in cocaine discrimination studies.

Apparatus and catheter maintenance-Monkeys were individually housed in ventilated, stainless steel chambers that also served as the experimental chamber as described above. In addition, each chamber was equipped with two syringe pumps (Model PHM-108, Med Associates). One pump (the "cocaine pump") was used to deliver responsecontingent cocaine injections through one lumen of the double-lumen catheter. The second pump (the "treatment pump") was used to deliver $0.1 \mathrm{~mL}$ infusions of saline or PAL-542 every $20 \mathrm{~min}$ from 12:00 noon each day until 11:00 a.m. the next morning through the second lumen of the double-lumen catheter. The intravenous (IV) catheter was protected by a system consisting of a custom-fitted jacket connected to a flexible stainless steel tether and fluid swivel (Lomir Biomedical, Malone, NY) that permitted monkeys to move freely in the cage. Catheter patency was periodically evaluated by IV ketamine $(5 \mathrm{mg} / \mathrm{kg})$ administration through the catheter lumen.

Cocaine vs. food choice procedures-Daily behavioral sessions were composed of five 20-min components separated by 5-min timeout periods. During each component, the left, food-associated key was illuminated red, and completion of an FR100 resulted in the delivery of a 1-g food pellet. The right, cocaine-associated key was illuminated green, and completion an FR10 resulted in the delivery of a cocaine injection. A different cocaine dose was available during each of the five successive components $(0,0.0032,0.01,0.032$ and 0.1 $\mathrm{mg} / \mathrm{kg} /$ injection during components $1-5$, respectively), and the cocaine dose was varied by differential activation of the pump duration and the resulting injection volume. Stimulus conditions on the cocaine-associated key were also varied by flashing the green lights on and off in $3 \mathrm{~s}$ cycles. Monkeys could complete up to a total of 10 ratio requirements between the food- and cocaine-associated keys during each component. Responding on either key reset the ratio requirement on the other key. Completion of each ratio requirement initiated a $3 \mathrm{~s}$ timeout, during which all stimulus lights were off, and responding had no scheduled consequences. During the "0" unit cocaine dose component, responses on this key were still recorded, still reset the FR requirement on the food-associated key, and completion of the FR requirement still counted as one of the 10 allotted ratios and initiated a $3 \mathrm{~s}$ timeout. If ten ratio requirements were completed before the 20-min component elapsed, then all stimulus lights were extinguished, and responding had no scheduled consequences for the remainder of that 20-min component. Choice behavior was considered stable when the lowest unit dose cocaine maintaining at least $80 \%$ cocaine choice varied by $₫ 0.5 \log$ units for three consecutive days.

Testing procedures-When cocaine vs. food choice was stable as defined above, test periods were started. Prior to each test and when the "treatment" pump infused saline, dependent variables of cocaine choice were assessed for three consecutive days to determine pretest "baseline" values. The test drug examined in this study was PAL-542 (0.032 - 0.1 $\mathrm{mg} / \mathrm{kg} / \mathrm{h}$ ). At the conclusion of each 7-day treatment period, saline infusions were reinstated for at least 5 days and until cocaine choice returned to pretest levels. 
Data analysis-The primary dependent variables for each component were (1) percent cocaine choice, defined as (number of choices completed on the cocaine-associated key $\div$ total number of choices completed on both the cocaine- and food-associated keys) $* 100$, and (2) total number of choices completed obtained from the last 3 days of each 7-day treatment period. These variables were then plotted as a function of cocaine dose and analyzed using two-way repeated-measures ANOVA with cocaine dose and PAL-542 dose as the main factors. Additional dependent variables collected during each session included total choices, total food choices, total cocaine choices, and total cocaine intake. These variables were analyzed by separate one-way repeated measures ANOVA with PAL-542 dose as the main factor. A significant ANOVA was followed by Holm-Sidak multiple comparisons post-hoc test to compare test conditions with baseline conditions and $p<0.05$ was considered significant.

\section{Drugs}

(-)-Cocaine $\mathrm{HCl}$ was provided by the National Institute on Drug Abuse Drug Supply Program (Bethesda, MD). (+)-Amphetamine hemisulfate and ( \pm )-fenfluramine $\mathrm{HCl}$ were purchased from Sigma (St. Louis, MO). Structures for other test compounds are shown in Figure 1, and were synthesized by Dr. Bruce Blough (Research Triangle Park, NC) as their fumarate salts. All drug doses are expressed as the salt forms listed above. All compounds were prepared in sterile saline and administered by IP injection in rats and by IM injection for discrimination studies in monkeys. For the cocaine vs. food choice studies, all drug solutions were passed through a sterile 0.2 micron filter (EMD Millipore, Billerica, MA) before IV administration.

\section{RESULTS}

Table 1 shows in vitro potency to promote substrate release via DA, NE, and 5HT transporters for three reference monoamine releasers (amphetamine, PAL-287 and fenfluramine) (Rothman et al., 2001; Rothman et al., 2005) and four novel monoamine releasers (PAL-542, PAL-544, PAL-571 and PAL-569). The novel compounds displayed more than an 800 -fold range of selectivities to promote DA vs. NE release. The most DA/ 5HT-selective compound was PAL-542 (64-fold higher potency for DA vs. NE), and the least DA/5HT-selective compound was PAL-569 (13-fold lower potency for DA vs. NE release). All four compounds displayed similar selectivities to release DA vs. 5HT, with slightly higher potency to release $5 \mathrm{HT}$.

\section{Effects of monoamine releasers in ICSS}

Effects of d-amphetamine, PAL-287, and fenfluramine on ICSS have been previously reported (Bauer et al., 2013). Figure 2 shows (A) dose effect and (B) time course effects of PAL-542, PAL-544, PAL-571, and PAL-569 on percent baseline stimulations. Additional data on potency and time course of all compounds at each individual frequency of brain stimulation are shown in supplemental figure 1. For these studies, the average MCR $( \pm$ SEM) during the first vehicle test was $63.00 \pm 4.92$. Doses of $1.0 \mathrm{mg} / \mathrm{kg}$ PAL-544 and 3.2 $\mathrm{mg} / \mathrm{kg}$ of PAL-542, PAL-544, and PAL-571 significantly decreased percent baseline stimulations compared to vehicle (F3.2,12.6=33.3, $\mathrm{p}<0.05)$. In general, all compounds 
decreased percent baseline stimulations during the first 10-30 min before dissipating at later time points depending on the compound (compound: $F_{4,16}=4.6, p<0.05$; time: $F_{3,12}=33.2$, $\mathrm{p}<0.05$; compound · time: $\mathrm{F} 12,48=2.4, \mathrm{p}<0.05)$.

\section{Effects of monoamine releasers in cocaine discrimination in rats}

Figure 3A shows maximal levels of cocaine-appropriate responding produced at any time by various doses of monoamine releasers in rats. Additional data on potency and time course of all compounds to produce cocaine-like discriminative stimulus effects and rate-altering effects are shown in supplemental figures 2 and 3. d-Amphetamine produced dosedependent and complete substitution for cocaine in all 6 rats that peaked after $10 \mathrm{~min}$ and dissipated after $300 \mathrm{~min}$, whereas fenfluramine failed to substitute for cocaine in any rat at any dose or time. PAL-287 produced intermediate effects, with $5.6 \mathrm{mg} / \mathrm{kg}$ substituting for cocaine in 3 of 5 rats after $100 \mathrm{~min}$. The novel compounds generally failed to produce cocaine-like discriminative stimulus effects. PAL-542, PAL-544, and PAL-569 did not substitute for cocaine at any dose or time in any rat, and PAL-571 $(3.2 \mathrm{mg} / \mathrm{kg})$ produced full substitution in only 1 out of 6 rats.

\section{Effects of monoamine releasers in cocaine discrimination in monkeys}

Figure 3B shows maximal levels of cocaine-appropriate responding produced at any time by various doses of monoamine releasers in rhesus monkeys. Additional data on potency and time course of all compounds to produce cocaine-like discriminative stimulus effects and rate-altering effects are shown in supplemental figures 4 and 5. As in rats, d-amphetamine produced dose-dependent and complete substitution in all monkeys (although cocaine-like effects of d-amphetamine lasted longer in monkeys than in rats), whereas fenfluramine failed to substitute for cocaine in any monkey at any time. The remaining compounds generally produced higher levels of cocaine-appropriate responding in monkeys than in rats, although the rank order of efficacy to substitute for cocaine was largely preserved. Thus, PAL-287, which substituted in 3 of 5 rats, substituted at some dose or time in all monkeys. Similarly, PAL-542, PAL-544 and PAL-569, which failed to substitute in any rats, produced full substitution in 2 of 5 monkeys (PAL-542 and PAL-544) or 3 of 5 monkeys (PAL-569). Only PAL-571 failed to follow this pattern, substituting for the discriminative stimulus effects of cocaine in only 1 rat and 1 monkey.

\section{Effects of PAL-542 on choice between cocaine and food in rhesus monkeys}

The effects of continuous 7-day treatment with PAL-542 $(0.032-0.1 \mathrm{mg} / \mathrm{kg} / \mathrm{h})$ on choice between cocaine and food are shown in Figure 4. Continuous 7-day treatment with 0.032 $\mathrm{mg} / \mathrm{kg} / \mathrm{h}$ PAL-542 did not significantly alter cocaine vs. food choice. Continuous 7-day treatment with $0.1 \mathrm{mg} / \mathrm{kg} / \mathrm{h}$ PAL-542 significantly increased cocaine choice of $0.01 \mathrm{mg} / \mathrm{kg} /$ injection cocaine (Panel A) (cocaine dose: $\mathrm{F}_{4,16}=353.2$, $\mathrm{p}<0.05$; cocaine dose $\cdot$ PAL-542 dose: $\mathrm{F}_{8,32}=2.9, \mathrm{p}<0.05$ ). Treatment with $0.1 \mathrm{mg} / \mathrm{kg} / \mathrm{h}$ PAL-542 also significantly (cocaine dose $\cdot$ PAL-542 dose: $F$ 8,32=2.9, $p<0.05$ ) decreased the number of choices completed when no cocaine and $0.0032 \mathrm{mg} / \mathrm{kg} /$ injection cocaine was available as the alternative to food and monkeys were allocating most of their behavior on the food associated key (Panel B). Furthermore, $0.1 \mathrm{mg} / \mathrm{kg} / \mathrm{h}$ PAL-542 treatment significantly increased the number of cocaine 
choices during the entire behavioral session compared to saline treatment conditions (Panel

C) (PAL-542 dose: F1.2,4.9=12.4, $\mathrm{p}<0.05)$.

\section{DISCUSSION}

The present study determined effects of monoamine releasers in assays of intracranial selfstimulation (ICSS) and cocaine discrimination in rats and of cocaine discrimination and cocaine self-administration in rhesus monkeys. Four novel DA/5HT releasers were examined, and these compounds varied along a continuum of selectivity for releasing DA/5HT vs. NE. There were two main findings. First, regardless of selectivity for releasing DA/5HT vs. NE in vitro, the novel compounds produced minimal or no facilitation of ICSS in rats and minimal or no substitution for the discriminative stimulus effects of cocaine in rats and monkeys. The weak efficacy of these compounds to produce abuse-related effects in these procedures is consistent with the relatively high potency of these compounds to promote 5HT release. Second, continuous treatment with PAL-542, which had the greatest selectivity for DA/5HT vs. NE, failed to decrease cocaine choice, and instead increased cocaine self-administration at a dose that also reduced food-maintained responding. This PAL-542 effect profile was similar to fenfluramine and PAL-287 effects on cocaine vs. food choice (Banks et al., 2011). Consequently, these results do not support the hypothesis that efficacy of dual DA/5HT releasers to reduce cocaine self-administration can be improved by increasing DA/5HT vs. NE selectivity.

\section{Role of DA, NE, and $5 \mathrm{HT}$ selectivity in abuse-related effects of monoamine releasers}

Monoamine releasers vary in their relative potencies to release DA, 5HT and NE. We have previously used an ICSS procedure in rats to examine a series of monoamine releasers with similar potencies to release DA and NE and varying selectivities to release DA/NE vs. 5HT, and we observed a correlation between DA/NE vs. 5HT selectivity and efficacy to produce abuse-related effects in ICSS (Bauer et al., 2013). For example, DA/NE- vs. 5HT-selective releasers, such as d-amphetamine and methamphetamine produced exclusively rateincreasing effects (Bauer et al., 2013; Elder, Montgomery, \& Rye, 1965). In contrast, the 5 HT- vs. DA/NE-selective releaser fenfluramine produces exclusively rate-decreasing effects (Bauer et al., 2013; Olds, 1995). Compounds with similar potencies to release all three monoamines, such as PAL-287 and 4-methylmethcathinone (mephedrone) produce a mixed profile of both rate-increasing and rate-decreasing effects (Bauer et al., 2013; Robinson, Agoglia, Fish, Krouse, \& Malanga, 2012). Similar correlations have also been established between in vitro selectivity to release DA/NE vs. 5HT and selectivity to increase extracellular DA vs. 5HT levels in rat nucleus accumbens (Baumann et al., 2011) or drug self-administration under a progressive-ratio schedule in rhesus monkeys (Wee et al., 2005). These results have been interpreted to suggest that 5HT release attenuates expression of DAmediated abuse-related effects of monoamine releasers.

Similar results have been reported in cocaine discrimination procedures. Thus, consistent with previous cocaine discrimination studies in both rats and monkeys from our laboratory (Caine et al., 2000; Negus et al., 2007) and others (Gold \& Balster, 1996; Kleven, Anthony, \& Woolverton, 1990), d-amphetamine produced full cocaine-like stimulus effects in this

Exp Clin Psychopharmacol. Author manuscript; available in PMC 2015 June 01. 
study, whereas fenfluramine did not. Furthermore, we have previously reported on the cocaine-like discriminative stimulus effects of PAL-287 in monkeys (Negus et al., 2007), and the present study confirmed and extended these findings in rats. Although the cocainelike effects of PAL-287 were qualitatively similar between monkeys and rats, PAL-287 was less efficacious to produce cocaine-like discriminative stimulus effects in rats than in monkeys. The reason for this discrepancy is not clear. Although a potential species difference is possible for PAL-287 effects and related monoamine releaser compounds (Weerts, Fantegrossi, \& Goodwin, 2007), another possibility could be related to the cocainetraining dose. In general, the breadth of drugs that substitute for a given training drug increase as the training dose of that drug decreases (Kantak et al., 1995; Schechter, 1997). Thus, the training dose of cocaine monkeys $(0.32 \mathrm{mg} / \mathrm{kg}$ IM) could have served as a functionally lower training dose than that used in rats $(5.6 \mathrm{mg} / \mathrm{kg} \mathrm{IP})$.

None of the novel dual DA/5HT releasers tested here produced reliable ICSS facilitation or substitution for the discriminative stimulus effects of cocaine. Consequently, these data are also consistent with the hypothesis that 5HT suppresses DA-mediated abuse-related effects in preclinical assays of ICSS and cocaine discrimination. These results also suggest that DA/5HT vs. NE selectivity has little influence on the abuse liability of dual DA/5HT releasers. However, there was some evidence for minor differences in the magnitude of ICSS facilitation or cocaine substitution related to NE. Specifically, the drugs most efficacious to facilitate ICSS or substitute for cocaine were the compounds with similar potencies to release DA and NE (PAL-287, PAL-571, PAL-544), suggesting that abuse liability of monoamine releasers may be associated with low selectivity for DA vs. NE release rather than with high selectivity for either DA or NE release. However, this conclusion should be regarded with caution for two reasons. First, the serotonergic effects of these compounds restricted our ability to resolve the contribution of NE selectivity to expression of abuse-related effects of monoamine releasers in ICSS and cocaine discrimination procedures. Second, this conclusion is not fully consistent with effects of monoamine uptake inhibitors in ICSS and cocaine discrimination procedures. For example, we and others have reported robust ICSS facilitation (Hall, Stellar, \& Kelley, 1990; Rosenberg, Carroll, \& Negus, 2013) and cocaine stimulus substitution in both rats (Broadbent, Michael, Riddle, \& Apple, 1991; Terry, Witkin, \& Katz, 1994) and monkeys (Kimmel et al., 2008; Kleven et al., 1990) by DA-selective uptake inhibitors (e.g. RTI-113 and GBR12909) as well as by mixed-action DA/NE uptake inhibitors (e.g. methylphenidate, cocaine). Nonetheless, the present results provide some evidence for a role of NE in contributing to abuse-related effects of monoamine releasers.

\section{Effects of a DA/5HT vs. NE releaser on cocaine choice}

Consistent with previous cocaine self-administration studies from our laboratory (Negus, 2003) and others (Nader \& Woolverton, 1991), cocaine maintained a dose-dependent increase in choice over a non-drug food alternative reinforcer. Previous studies have reported the efficacy of DA/NE vs. 5HT selective releasers in general, and d-amphetamine in particular, to decrease cocaine choice in both nonhuman primates and rats (Banks, Blough, \& Negus, 2013; Negus, 2003; Thomsen, Barrett, Negus, \& Caine, 2013). These effects of monoamine releasers in preclinical choice procedures are supported by 
monoamine releaser effects in clinical trials (Grabowski et al., 2001; Mooney et al., 2009). Moreover, these results also support the utility of preclinical choice procedures as an experimental tool to assess and predict candidate medications for the treatment of cocaine addiction (Banks \& Negus, 2012).

Based on the results from the ICSS and cocaine discrimination assays, PAL-542 emerged as a candidate compound to test in the cocaine vs. food choice procedure because of its high DA/5HT vs. NE-selectivity and low abuse liability. However, in contrast to the previously reported d-amphetamine effects (Banks, Blough, \& Negus, 2013; Negus, 2003), continuous treatment with PAL-542 produced a small but significant increase in $0.01 \mathrm{mg} / \mathrm{kg} /$ injection cocaine preference at a dose that also significantly decreased food-maintained responding. These PAL-542 effects on cocaine choice in the present study were similar to previous effects observed after continuous PAL-287 or fenfluramine treatment (Banks et al., 2011). In that study, 7-day treatment with PAL-287 or fenfluramine also produced increases in cocaine vs. food choice and decreased overall rates of operant responding. Consequently, reducing the potency to release NE does not improve the efficacy of dual DA/5HT releasers to reduce cocaine self-administration.

\section{Supplementary Material}

Refer to Web version on PubMed Central for supplementary material.

\section{Acknowledgments}

DISCLOSURES AND ACKNOWLEDGEMENTS: Research reported in this publication was supported by the National Institute on Drug Abuse of the National Institutes of Health under Award Numbers R01DA026946, R01DA012970, F30DA034478, and by the Intramural Research Program of the National Institute on Drug Abuse. The content is solely the responsibility of the authors and does not necessarily represent the official views of the National Institutes of Health.

Banks, Bauer, Blough, Baumann, Rothman, and Negus participated in the research design. Banks, Bauer, and Partilla conducted the experiments. Blough synthesized and contributed the novel compounds. Banks, Bauer, Baumann, Rothman, and Partilla performed the data analysis. Banks, Bauer, Blough, Rothman, Baumann, Partilla, and Negus wrote or contributed to the writing of the manuscript. All authors have read and approved the final manuscript version.

We appreciate the technical assistance of Jennifer Gough and Crystal Reyns. We also acknowledge Kevin Costa for writing the original versions of the computer programs.

\section{REFERENCES}

Anderson KG, Winger G, Woods J, Woolverton WL. Reinforcing and discriminative-stimulus effects of ephedrine isomers in rhesus monkeys. Drug and Alcohol Dependence. 2001; 65:45-53. doi: http://dx.doi.org/10.1016/S0376-8716(01)00143-0. [PubMed: 11714589]

Banks ML, Blough BE, Fennell TR, Snyder RW, Negus SS. Effects of phendimetrazine treatment on cocaine vs food choice and extended-access cocaine consumption in rhesus monkeys. Neuropsychopharmacology. 2013a; 38:2698-2707. doi: 10.1038/npp.2013.180. [PubMed: 23893022]

Banks ML, Blough BE, Fennell TR, Snyder RW, Negus SS. Role of phenmetrazine as an active metabolite of phendimetrazine: Evidence from studies of drug discrimination and pharmacokinetics in rhesus monkeys. Drug and Alcohol Dependence. 2013b; 130:158-166. doi: http://dx.doi.org/ 10.1016/j.drugalcdep.2012.10.026. [PubMed: 23211394] 
Banks ML, Blough BE, Negus SS. Effects of monoamine releasers with varying selectivity for releasing dopamine/norepinephrine versus serotonin on choice between cocaine and food in rhesus monkeys. Behavioural Pharmacology. 2011; 22:824-836. doi: 10.1097/FBP.0b013e32834d63ac. [PubMed: 22015808]

Banks ML, Blough BE, Negus SS. Effects of 14-day treatment with the schedule III anorectic phendimetrazine on choice between cocaine and food in rhesus monkeys. Drug and Alcohol Dependence. 2013; 131:204-213. doi: http://dx.doi.org/10.1016/j.drugalcdep.2013.05.005. [PubMed: 23726979]

Banks ML, Negus SS. Preclinical determinants of drug choice under concurrent schedules of drug selfadministration. Advances in Pharmacological Sciences. 2012; 2012:281768. doi: 10.1155/2012/281768. [PubMed: 23243420]

Bauer CT, Banks ML, Blough BE, Negus SS. Use of intracranial self-stimulation to evaluate abuserelated and abuse-limiting effects of monoamine releasers in rats. British Journal of Pharmacology. 2013; 168:850-862. doi: 10.1111/j.1476-5381.2012.02214.x. [PubMed: 22978626]

Baumann MH, Ayestas MA, Partilla JS, Sink JR, Shulgin AT, Daley PF, Cozzi NV. The designer methcathinone analogs, mephedrone and methylone, are substrates for monoamine transporters in brain tissue. Neuropsychopharmacology. 2012; 37:1192-1203. [PubMed: 22169943]

Baumann MH, Clark RD, Woolverton WL, Wee S, Blough BE, Rothman RB. In vivo effects of amphetamine analogs reveal evidence for serotonergic inhibition of mesolimbic dopamine transmission in the tat. The Journal of Pharmacology and Experimental Therapeutics. 2011; 337:218-225. doi: 10.1124/jpet.110.176271. [PubMed: 21228061]

Broadbent J, Michael EK, Riddle EE, Apple JB. Involvement of dopamine uptake in the discriminative stimulus effects of cocaine. Behavioural Pharmacology. 1991; 2:187-197. [PubMed: 11224062]

Caine SB, Negus SS, Mello NK, Bergman J. Effects of dopamine D -like and D -like agonists in rats trained to discriminate cocaine from saline: Influence of experimental history. Experimental and Clinical Psychopharmacology. 2000; 8:404-414. doi: 10.1037/1064-1297.8.3.404. [PubMed: 10975632]

Carlezon WA, Chartoff EH. Intracranial self-stimulation (ICSS) in rodents to study the neurobiology of motivation. Nature Protocols. 2007; 2:2987-2995. doi: http://www.nature.com/nprot/ journal/v2/n11/suppinfo/nprot.2007.441_S1.html.

Chiodo KA, Läck CM, Roberts DCS. Cocaine self-administration reinforced on a progressive ratio schedule decreases with continuous d-amphetamine treatment in rats. Psychopharmacology. 2008; 200:465-473. doi: 10.1007/s00213-008-1222-8. [PubMed: 18604521]

Czoty PW, Gould RW, Martelle JL, Nader MA. Prolonged attenuation of the reinforcing strength of cocaine by chronic d-amphetamine in rhesus monkeys. Neuropsychopharmacology. 2011; 36:539547. [PubMed: 20962765]

Elder ST, Montgomery NP, Rye MM. Effects of food deprivation and methamphetamine on fixed-ratio schedules if intracranial self-stimulation. Psychological Reports. 1965; 16:1225-1233. doi: 10.2466/pr0.1965.16.3c.1225.

Gold LH, Balster RL. Evaluation of the cocaine-like discriminative stimulus effects and reinforcing effects of modafinil. Psychopharmacology. 1996; 126:286-292. doi: 10.1007/BF02247379. [PubMed: 8878344]

Grabowski J, Rhoades H, Schmitz J, Stotts A, Daruzska LA, Creson D, Moeller FG. Dextroamphetamine for cocaine-dependence treatment: a double-blind randomized clinical trial. Journal of Clinical Psychopharmacology. 2001; 21:522-526. [PubMed: 11593078]

Grabowski J, Rhoades H, Stotts A, Cowan K, Kopecky C, Dougherty A, Schmitz J. Agonist-like or antagonist-like treatment for cocaine dependence with methadone for heroin dependence: Two double-blind randomized clinical trials. Neuropsychopharmacology. 2004; 29:969-981. [PubMed: 15039761]

Grabowski J, Shearer J, Merrill J, Negus SS. Agonist-like, replacement pharmacotherapy for stimulant abuse and dependence. Addictive Behaviors. 2004; 29:1439-1464. doi: http://dx.doi.org/10.1016/ j.addbeh.2004.06.018. [PubMed: 15345275]

Greenwald MK, Lundahl LH, Steinmiller CL. Sustained release d-amphetamine reduces cocaine but not "speedball"-seeking in buprenorphine-maintained volunteers: A test of dual-agonist 
pharmacotherapy for cocaine/heroin polydrug abusers. Neuropsychopharmacology. 2010; 35:2624-2637. [PubMed: 20881947]

Hall FS, Stellar JR, Kelley AE. Acute and chronic desipramine treatment effects on rewarding electrical stimulation of the lateral hypothalamus. Pharmacology, Biochemistry, and Behavior. 1990; 37:277-281. doi: http://dx.doi.org/10.1016/0091-3057(90)90334-E.

Kamien JB, Woolverton WL. A pharmacological analysis of the discriminative stimulus properties of d-amphetamine in rhesus monkeys. The Journal of Pharmacology and Experimental Therapeutics. 1989; 248:938-946. [PubMed: 2649658]

Kampman KM, Rukstalis M, Pettinati H, Muller E, Acosta T, Gariti P, O'Brien CP. The combination of phentermine and fenfluramine reduced cocaine withdrawal symptoms in an open trial. Journal of Substance Abuse Treatment. 2000; 19:77-79. doi: http://dx.doi.org/10.1016/ S0740-5472(99)00076-8. [PubMed: 10867304]

Kantak KM, Edwards MA, Spealman RD. Effects of N-methyl-D-aspartate antagonists in rats discriminating different doses of cocaine: comparison with direct and indirect dopamine agonists. The Journal of Pharmacology and Experimental Therapeutics. 1995; 274:657-665. [PubMed: 7636725]

Kimmel HL, Negus SS, Wilcox KM, Ewing SB, Stehouwer J, Goodman MM, Howell LL. Relationship between rate of drug uptake in brain and behavioral pharmacology of monoamine transporter inhibitors in rhesus monkeys. Pharmacology, Biochemistry, and Behavior. 2008; 90:453-462. doi: http://dx.doi.org/10.1016/j.pbb.2008.03.032.

Kleven MS, Anthony EW, Woolverton WL. Pharmacological characterization of the discriminative stimulus effects of cocaine in rhesus monkeys. The Journal of Pharmacology and Experimental Therapeutics. 1990; 254:312-317. [PubMed: 2195158]

Lamas X, Negus SS, Hall E, Mello NK. Relationship between the discriminative stimulus effects and plasma concentrations of intramuscular cocaine in rhesus monkeys. Psychopharmacology. 1995; 121:331-338. doi: 10.1007/BF02246072. [PubMed: 8584615]

Mooney ME, Herin DV, Schmitz JM, Moukaddam N, Green CE, Grabowski J. Effects of oral methamphetamine on cocaine use: A randomized, double-blind, placebo-controlled trial. Drug and Alcohol Dependence. 2009; 101:34-41. doi: http://dx.doi.org/10.1016/j.drugalcdep.2008.10.016. [PubMed: 19058926]

Nader M, Woolverton W. Effects of increasing the magnitude of an alternative reinforcer on drug choice in a discrete-trials choice procedure. Psychopharmacology. 1991; 105:169-174. [PubMed: 1796123]

Negus SS. Rapid assessment of choice between cocaine and food in rhesus monkeys: Effects of environmental manipulations and treatment with d-amphetamine and flupenthixol. Neuropsychopharmacology. 2003; 28:919-931. [PubMed: 12637948]

Negus SS, Mello NK, Blough BE, Baumann MH, Rothman RB. Monoamine releasers with varying selectivity for dopamine/norepinephrine versus serotonin release as candidate "agonist" medications for cocaine dependence: Studies in assays of cocaine discrimination and cocaine selfadministration in rhesus monkeys. The Journal of Pharmacology and Experimental Therapeutics. 2007; 320:627-636. doi: 10.1124/jpet.106.107383. [PubMed: 17071819]

Olds ME. Dopamine agonists prevent or counteract the suppression of brain stimulation reward by fenfluramine. Pharmacology, Biochemistry, and Behavior. 1995; 50:41-48. doi: http://dx.doi.org/ 10.1016/0091-3057(94)00240-J.

Risner M, Jones BE. Role of noradrenergic and dopaminergic processes in amphetamine selfadministration. Pharmacology, Biochemistry, and Behavior. 1976; 5:477-482.

Robinson JE, Agoglia AE, Fish EW, Krouse MC, Malanga CJ. Mephedrone (4-methylmethcathinone) and intracranial self-stimulation in C57BL/6J mice: Comparison to cocaine. Behavioural Brain Research. 2012; 234:76-81. doi: http://dx.doi.org/10.1016/j.bbr.2012.06.012. [PubMed: 22728726]

Rosenberg MB, Carroll FI, Negus SS. Effects of monoamine reuptake inhibitors in assays of acute pain-stimulated and pain-depressed behavior in rats. Journal of Pain. 2013; 14:246-259. doi: http://dx.doi.org/10.1016/j.jpain.2012.11.006. [PubMed: 23332494] 
Rothman RB, Baumann MH, Dersch CM, Romero DV, Rice KC, Carroll FI, Partilla JS. Amphetamine-type central nervous system stimulants release norepinephrine more potently than they release dopamine and serotonin. Synapse. 2001; 39:32-41. [PubMed: 11071707]

Rothman, RB.; Blough, BE.; Baumann, MH. Dopamine/serotonin releasers as medications for stimulant addictions. In: Giuseppe Di Giovann, VDM.; Ennio, E., editors. Progress in Brain Research. Vol. Vol. 172. Elsevier; 2008. p. 385-406.

Rothman RB, Blough BE, Woolverton WL, Anderson KG, Negus SS, Mello NK, Baumann MH. Development of a rationally designed, low abuse potential, biogenic amine releaser that suppresses cocaine self-administration. The Journal of Pharmacology and Experimental Therapeutics. 2005; 313:1361-1369. doi: 10.1124/jpet.104.082503. [PubMed: 15761112]

Rush CR, Stoops WW, Sevak RJ, Hays LR. Cocaine choice in humans during D-amphetamine maintenance. Journal of Clinical Psychopharmacology. 2010; 30:152-159. doi: 10.1097/JCP. 0b013e3181d21967. [PubMed: 20520288]

Schechter MD. Discriminative characteristics of high and low cocaine administration: Effect of other psychostimulants. Pharmacology, Biochemistry, and Behavior. 1997; 56:457-463. doi: http:// dx.doi.org/10.1016/S0091-3057(96)00301-2.

Stoops WW, Rush CR. Agonist replacement for stimulant dependence: A review of clinical research. Current Pharmaceutical Design. 2013; 19:7026-7035. [PubMed: 23574440]

Terry P, Witkin JM, Katz JL. Pharmacological characterization of the novel discriminative stimulus effects of a low dose of cocaine. The Journal of Pharmacology and Experimental Therapeutics. 1994; 270:1041-1048. [PubMed: 7932151]

Thomsen M, Barrett AC, Negus SS, Caine SB. Cocaine versus food choice procedure in rats: environmental manipulations and effects of amphetamine. Journal of the Experimental Analysis of Behavior. 2013; 99:211-233. doi: 10.1002/jeab.15. [PubMed: 23319458]

Tongjaroenbuangam W, Meksuriyen D, Govitrapong P, Kotchabhakdi N, Baldwin BA. Drug discrimination analysis of pseudoephedrine in rats. Pharmacology, Biochemistry, and Behavior. 1998; 59:505-510. doi: http://dx.doi.org/10.1016/S0091-3057(97)00459-0.

Wee S, Anderson KG, Baumann MH, Rothman RB, Blough BE, Woolverton WL. Relationship between the serotonergic activity and reinforcing effects of a series of amphetamine analogs. The Journal of Pharmacology and Experimental Therapeutics. 2005; 313:848-854. doi: 10.1124/jpet. 104.080101. [PubMed: 15677348]

Weerts EM, Fantegrossi WE, Goodwin AK. The value of nonhuman primates in drug abuse research. Experimental and Clinical Psychopharmacology. 2007; 15:309-327. doi: 10.1037/1064-1297.15.4.309. [PubMed: 17696678]

Woolverton WL. Evaluation of the role of norepinephrine in the reinforcing effects of psychomotor stimulants in rhesus monkeys. Pharmacology, Biochemistry, and Behavior. 1987; 26:835-839.

Exp Clin Psychopharmacol. Author manuscript; available in PMC 2015 June 01. 

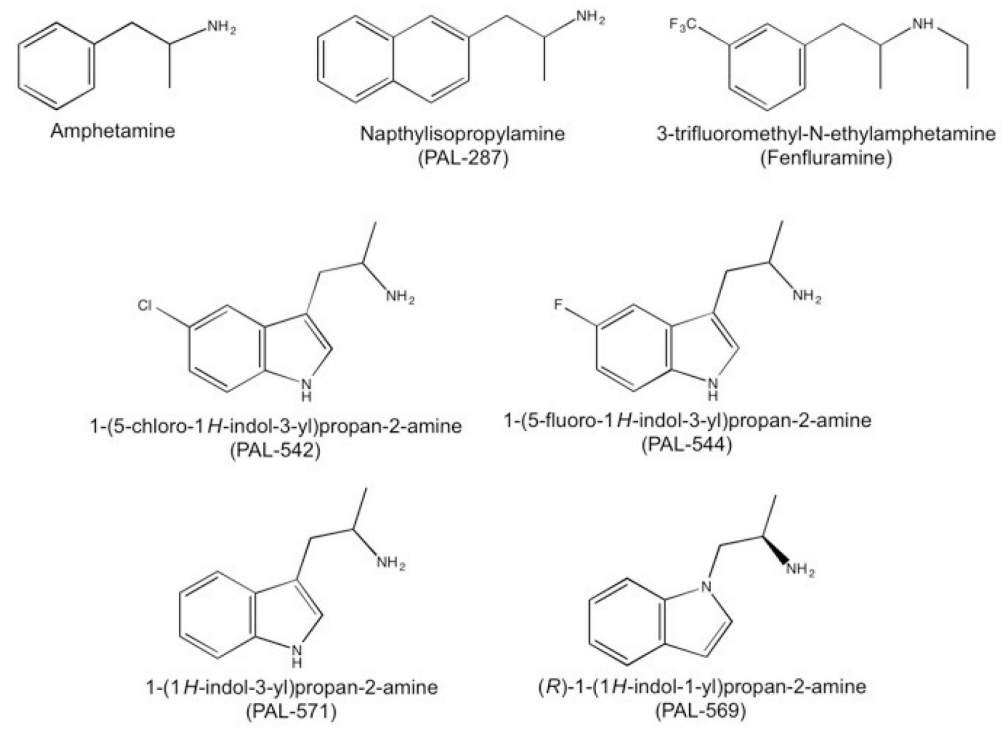

Figure 1.

Structures of the monoamine releasers tested in this study. Potencies of these compounds to release DA, NE, and 5HT in vitro are reported in Table 1. 

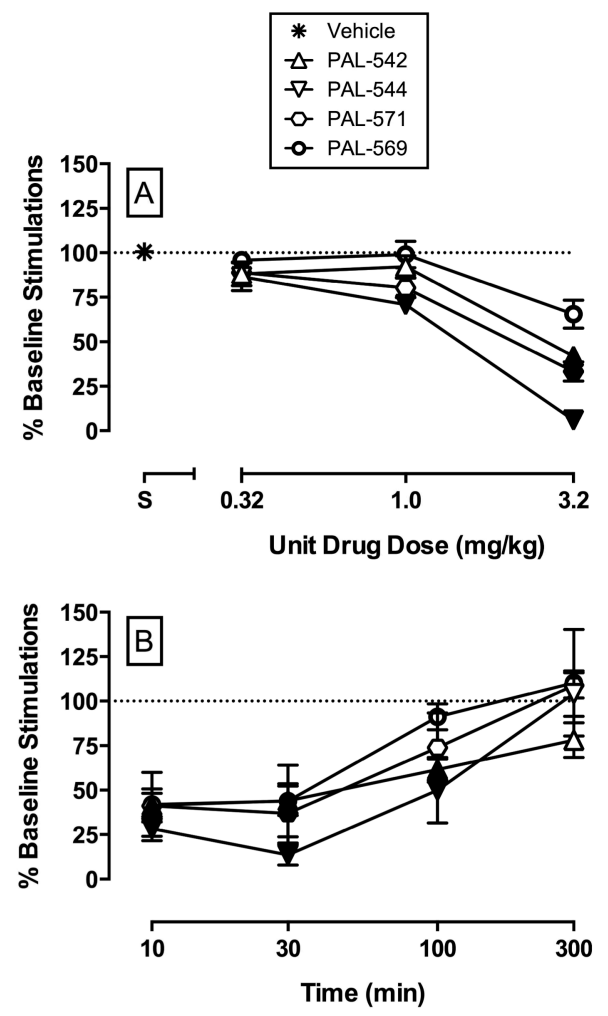

Figure 2.

Summary effects of PAL-542, PAL-544, PAL-571, and PAL-569 on intracranial selfstimulation in rats. Group mean data are expressed as percent pre-drug baseline number of stimulations delivered across all frequencies of brain stimulation. Panel A shows potencies and efficacious of test compounds. Panel B shows time course effects for test compounds. All symbols represent mean \pm s.e.m. of 5 rats. Filled symbols represent doses (A) or time (B) after test compound administration at which percent baseline stimulations were statistically $(p<0.05)$ different from vehicle $(\mathrm{A})$ or baseline $(\mathrm{B})$. 


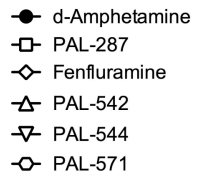

A. Rat Discrimination

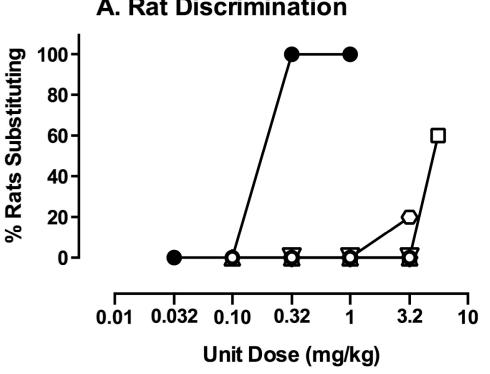

B. Monkey Discrimination

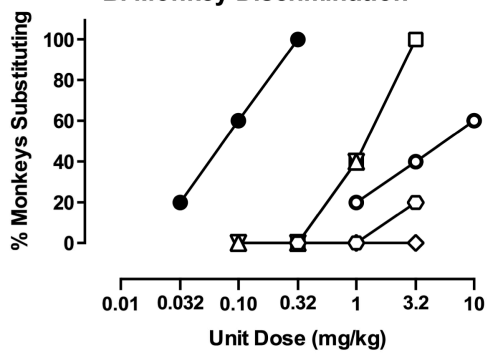

Figure 3.

Cocaine-like discriminative stimulus effects of d-amphetamine, PAL-287, fenfluramine, PAL-542, PAL-544, PAL-571, and PAL-569 in a two-key food-reinforced assay of cocaine vs. saline discrimination procedure in rats (A) and rhesus monkeys (B). Abscissae: Drug dose (milligrams per kilogram, log scale). Ordinates: cumulative percentage of rats or monkeys in which complete substitution for cocaine was observed ( $890 \%$ cocaineappropriate responding) at some dose or time. All compounds were tested in 5-6 rats and 5 rhesus monkeys. 

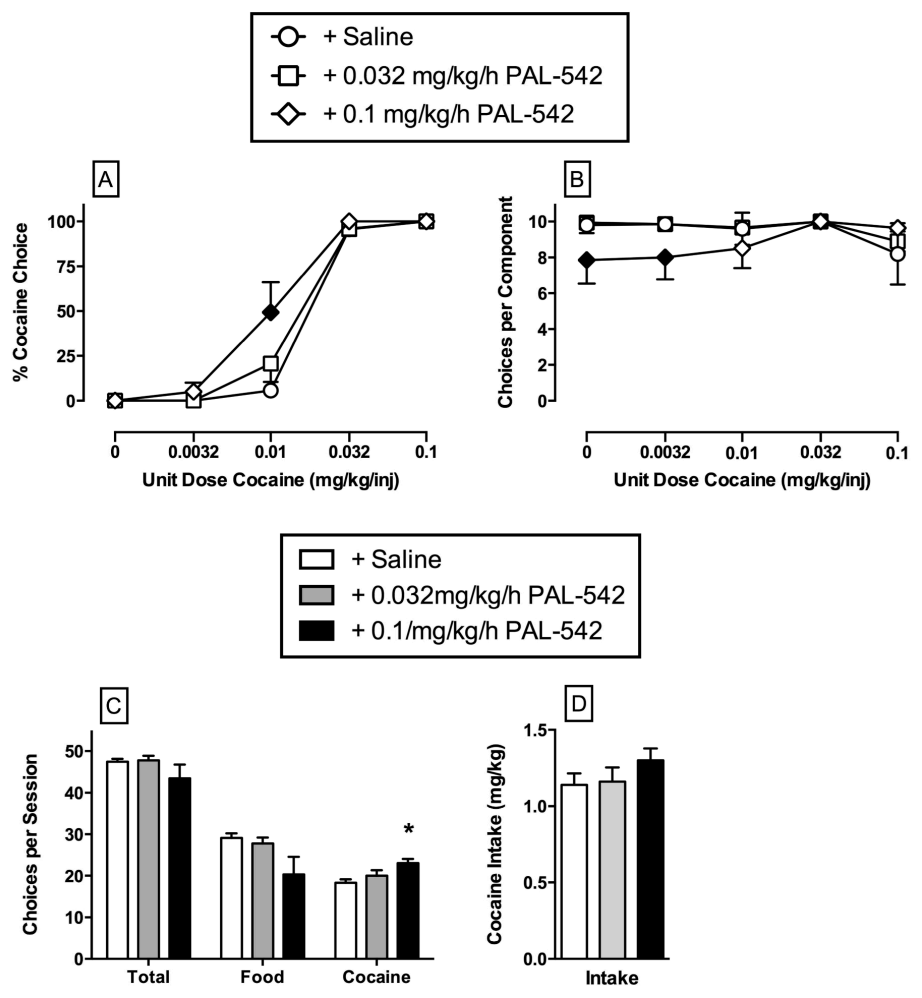

Figure 4.

Effects of continuous 7-day treatment with PAL-542 $(0.032-0.1 \mathrm{mg} / \mathrm{kg} / \mathrm{h})$ on choice between cocaine and food in rhesus monkeys $(\mathrm{N}=5)$. Top Ordinates: percent cocaine choice (left) or the number of choices completed per component (right) during treatment with saline or increasing doses of PAL-542. Top Abscissae: unit dose of cocaine in milligrams per kilogram per injection (log scale). Bottom panels show total choices, food choices, cocaine choices and cocaine intake during choice sessions before or during 7-day treatment with PAL-542. Bottom Left Ordinate: Number of choices per session. Bottom Right Ordinate: cocaine intake in milligrams per kilogram per day during choice sessions. Bottom Abscissae: experimental endpoint. All points and bars represent group mean data \pm s.e.m. obtained during days 5-7 of each 7-day treatment period. Saline points and bars represent the mean \pm s.e.m. of mean data obtained during the 3 days preceding PAL-542 treatment when saline was infused through the "treatment" lumen of the double lumen catheter. Filled symbols and asterisks indicate statistical significant $(\mathrm{p}<0.05)$ compared to "+ saline" conditions. 


\section{Table 1}

$\mathrm{EC}_{50}$ values ( $\mathrm{nM} \pm$ s.e.m.) to promote substrate release through $\mathrm{DA}, 5 \mathrm{HT}$ and $\mathrm{NE}$ transporters in an in vitro rat synaptosome preparation. The ratios of $\mathrm{DA} \mathrm{EC}_{50} / \mathrm{NE} \mathrm{EC}_{50}$ and $\mathrm{DA} \mathrm{EC}_{50} / 5 \mathrm{HT} \mathrm{EC}_{50}$ are also shown. Ratio values $<1$ indicate selectivity to promote release via DA transporters than via NE or $5 \mathrm{HT}$ transporters. Data for d-amphetamine, PAL-287 and fenfluramine have been published previously.

\begin{tabular}{|l|l|l|l|l|l|}
\hline Compound & $\begin{array}{l}\text { DA } \\
\mathbf{E C}_{\mathbf{5 0}}\end{array}$ & $\begin{array}{l}\text { NE } \\
\mathbf{E C}_{\mathbf{5 0}}\end{array}$ & $\begin{array}{l}\text { 5HT } \\
\mathbf{E C}_{\mathbf{5 0}}\end{array}$ & $\mathbf{D A} / \mathbf{N E}$ & DA/5HT \\
\hline d-Amphetamine $^{a}$ & $24.8 \pm 3.5$ & $7.2 \pm 0.4$ & $1765 \pm 94$ & 3.51 & 0.01 \\
\hline PAL-287 $^{b}$ & $12.6 \pm 0.4$ & $11.1 \pm 0.9$ & $3.4 \pm 0.2$ & 1.14 & 3.71 \\
\hline $\mathbf{( \pm ) - F e n f l u r a m i n e ~}^{a}$ & $>10,000$ & $739 \pm 57$ & $79.3 \pm 11.5$ & $>13.53^{*}$ & $>126.10^{*}$ \\
\hline PAL-542 & $54 \pm 2$ & $3434 \pm 516$ & $16 \pm 2$ & 0.016 & 3.38 \\
\hline PAL-544 & $32 \pm 1$ & $126 \pm 18$ & $19 \pm 1$ & 0.25 & 1.68 \\
\hline PAL-571 & $173 \pm 10$ & $79 \pm 19$ & $28 \pm 3$ & 2.19 & 6.18 \\
\hline PAL-569 & $1062 \pm 54$ & $81 \pm 9$ & $177 \pm 20$ & 13.11 & 6.00 \\
\hline
\end{tabular}

Fenfluramine selectivity is approximated using $10,000 \mathrm{nM}$ as the potency for releasing DA.

$a_{\text {(Rothman et al., 2001) }}$

$b_{\text {(Rothman et al., 2005) }}$ 